\title{
Uma Análise dos Determinates Microeconômicos do Auto Emprego no Estado de Mato Grosso
}

Keiko Martins Tamashiro* Udilmar Carlos Zabot

Resumo: Neste estudo, avaliou-se os determinantes microeconômicos do auto emprego no estado de Mato Grosso, considerando as mudanças estruturais ocorridas no mercado de trabalho do estado nos últimos anos. A partir de dois cortes temporais, em 2004 e em 2012, procura-se avaliar as alterações nos condicionantes do auto emprego e os efeitos sobre a dinâmico da mercado de trabalho em Mato Grosso. Foi considerado um modelo de probabilidade linear, cujas variáveis explicativas representam características socioeconômicas dos indivíduos, segundo informações da PNAD. Observa-se que o nível de educação é importante ao explicar o auto emprego no estado, em que quanto maior o grau de escolaridade, menores são as chances deste tipo de ocupação. Ademais, os resultados indicam que no período mais recente, as variáveis gênero e raça se tornaram mais significativas ao explicar o auto emprego. Assim, as evidências demonstram que, para o mercado de trabalho de Mato Grosso, o auto emprego é melhor explicado pelos argumentos da teoria push, em que a opção por este tipo de ocupação é mais uma resposta às dificuldades de inserção do mercado formal do que à busca por melhores oportunidades.

Palavras-Chave: Mercado de Trabalho, Mato Grosso, Auto Emprego.

Abstract: In this paper, we evaluate the microeconomic determinants of self employment in Mato Grosso, Brazil, considering the structural changes that occur in labor market lately. From two cross sections, in 2004 and 2012, we evaluate the changes in the self employment conditions and the effects on the labor market dynamics. We argue that the education level is important to explain the self employment. Finally, the results shows that recently, the gender and other determiants become more signficant to explain the self employment. The evidences indicate that, for the Mato Grosso labor market, the self employment is due to the push theory arguments, where the option for this is more a response to the labor market restriction than a look for better oportunities.

Key-Words: Labor Market, Mato Grosso, Self Employment.

JEL: E24, J10, J30.

\footnotetext{
* Graduada no curso de Economia na área de Ciências Sociais Aplicadas na Universidade do Estado de Mato Grasso/Sinop.
} 


\section{Introdução}

A economia do estado de Mato Grosso vem se desenvolvendo nas últimas décadas baseando-se principalmente na dinâmica do agronegócio, sobretudo da produção de grãos e pecuária. O setor agrícola do estado tem se modernizado rapidamente, alcançando níveis elevados de produtividade e intensificando os investimentos em capital físico e tecnologia de produção.

Um dos reflexos desta crescente modernização do setor é a redução da intensidade do fator trabalho no processo produtivo, que resulta na transferência de mão-de-obra para outras atividades econômicas, consequentemente, um deslocamento de trabalhadores de áreas agrícolas para áreas urbanas. Aliado a isto, o crescimento de algumas cidades e a expansão das atividades econômicas ligadas ao setor de serviços tem proporcionado uma mudança significativa na estrutura do mercado de trabalho no estado.

Neste sentido, uma das mudanças observadas no mercado de trabalho em Mato Grosso é o crescimento da ocupação considerada auto emprego, situação na qual o indíviduo exerce uma atividade de trabalho com relativa autonomia, sem vinculos trabalhistas, seja com outras pessoas ou com empresas. Resultante de alterações nas relações trabalhistas, o crescimento da ocupação considerada auto emprego surge como alternativa à falta de espaço no mercado de trabalho formal. Em outros termos, considerando os efeitos negativos do desemprego, o auto emprego tem sido considerado uma alternativa à falta de oportunidades satisfatórias no mercado de trabalho formal.

Cabe ressaltar que os motivos para a desocupação são diversas, e podem decorrer da falta de vagas no mercado formal ou ausência de qualificação suficiente ou ainda pela escassez de capital técnico e humano (PAMPLONA, 2001). Dessa forma, o auto emprego surge para contornar essas dificuldades, podendo ocorrer tanto em atividades agrícolas, como em áreas diversas, como negócios e comércio. Uma segunda justificativa para o auto emprego é a busca por remuneração superior àquela obtida em vagas formais de trabalho assalariado.

Posto isto, a questão central deste estudo é a avaliação das condicionantes microeconômicas do auto emprego em Mato Grosso. Considerando que a ocupação dita auto emprego tem aumentado no estado nos últimos anos, e que do ponto de vista teórico, isso se justifica tanto pela falta de vagas no mercado formal quanto pela busca por melhores níveis de renda, busca-se analisar os fatores determinantes da opção pelo auto emprego no mercado de trabalho em Mato Grosso.

Assim, além desta introdução, o artigo está estruturado da seguinte maneira. A segunda seção apresenta uma breve revisão de literatura sobre a questão do auto emprego, evidenciando os aspectos socioeconômicos determinantes deste tipo de relação trabalhista. A terceira seção apresenta a estratégia empírica e o modelo econométrico utilizado para a análise. A quarta seção traz os resultados empíricos e as análises econômicas relacionadas. Por fim, tecem-se algumas considerações finais.

\section{O Auto Emprego: Definição e Características}

Revista de Estudos Sociais | Ano 2016, N. 37, V. 18, Pag. 59 
De acordo com Gomes (2009), considera-se auto empregado, o indivíduo que possui a característica da autonomia na atividade econômica que exerce, onde o mesmo é detentor do capital físico e humano. O auto emprego pode manifestar-se nos meios rurais ou urbanos, em atividades ligadas aos serviços ou ao comércio. O rendimento deste tipo de atividade, normalmente, não gera excedentes, ou seja, a atividade é exercida com fins de subsistência. Entretanto, o auto emprego pode ser opção para individuos que buscam obter ganhos maiores àqueles oferecidos nas vagas de trabalho assalariado (Gomes, 2009). A caracteristica central na definição do auto emprego é a ausência de relações trabalhistas entre empregado e empregador, ou seja, na ocupação de auto emprego, o indivíduo não possui vínculos com normas da legislação trabalhista (Pamplona, 2001).

Gomes (2009) ressalta ainda que para uma subcategoria, denominada de zona cinzenta, sendo composta por auto empregados que não podem ser considerados na pesquisa, uma vez que, sua classificação está entre o auto emprego e o trabalho assalariado. Consequentemente haverá uma divergência ao aceitá-los como auto empregados. Assim, alguns indivíduos auto empregados "possuem vinculos empregatícios e recebem salários fixos mensais, ou seja, seus rendimentos seriam pré-determinados, e o risco é administrado pelo empregador, mesmo atuando por conta própria..." (GOMES, 2009, p. 22).

Para tanto, empregados que estão em ativiades denominadas por Muehlberger e Pasqua (2006) de subconcentração e outsourcing, compõem a zona cinzenta, uma vez que, esses indivíduos estão exercendo atividades tercerizadas, assim, eles dependem da firma que os contrataram. Nesse sentido, o indivíduo ao exercer atividades tercerizadas, exercem uma relaçao denominada pela OIT (2003) de auto emprego dependente. O auto emprego dependente, está não apenas relacionado ao emprego de relações trabalhistas, tampouco os pagamentos prefixados, mas sim aos termos do contrato, aos locais e horários de serviço, e o conteúdo do trabalho. Na Itália, por exemplo, essa relação é denomiado de "contratos de colaboração contínua e coordenada" (Muehlberger e Pasqua, 2006, p.4).

Nesse sentido, ao ter como definição que o auto emprego é uma atividade que possui como principal característica a autonomia, a não geração de excedentes e a ausência de relações trabalhistas, é inaceitável considerar nesse meio os indivíduos que possui tais caracteríscas, porém possuem salários préfixados. Esses indivíduos devem ser caracterizados na zona cinzenta, pois, apesar de aparentemente estarem auto empregados, possuem alto grau de subordinação e dependência. Assim, para efeito de aprimoração e precisão do trabalho, desconsidera-se dados referentes a esses indivíduos da pesquisa.

\subsection{Teorias do Auto Emprego}

Existem duas teorias que predominam e buscam explicar o exercício do auto emprego, de acordo com fatores que determinam a entrada e saída de indivíduos deste tipo de ocupação, conhecidas como push e pull. Essas teorias possuem maior destaque por serem mais abrangentes, visto que agrupam os fatores que levam o indivíduo para o auto emprego. Segundo Pamplona (2001) 
e Parker (2004) os fatores que conduzem ao auto emprego estão relacionados à situação econômica, à pré-disposição para o auto emprego e aos fatores externos.

Na teoria de pull, considera-se que os auto empregados, são atraídos puxados - por fatores considerados como positivos ou favoráveis. Para Pamplona (2001) sob a ótica da teoria de pull o auto emprego é uma resposta conciliadora para a dinâmica do mercado de trabalho, pois atua como fonte de geração de emprego e crescimento econômico. Nesse contexto, Silva (2008) completa

No que se refere às razões que levam um indivíduo a assumir a condição de autoempregado, Hughes (2003) observa a existência de um debate inconclusivo entre duas correntes: os que consideram que o aumento na taxa de auto-emprego nas últimas décadas se deve a um movimento voluntário dos indivíduos (um movimento do tipo pull), representando uma tendência cultural contemporânea (SILVA, 2008 p.218).

Por esse ângulo, dada a definição da teoria de pull, conforme ressalta Gomes (2009), o auto emprego é visto pelo indivíduo como uma oportunidade para o aumento da renda, geralmente com recompensas superiores a de um empregado assalariado. Dessa forma, dada a dinâmica do mercado de trabalho e considerando as condições econômicas, o auto emprego torna-se alternativa para os indíviduos que buscam independencia no mercado de trabalho.

Entretanto, a teoria de push é oposta à de pull, uma vez que possui um viés pessimista, ou seja, a teoria de push considera que os indivíduos são empurrados para o auto emprego. Portanto, a teoria push considera que os indivíduos são empurados para o auto emprego por algum fator socioeconômico. Henrekson (2004) e Parker (2004) argumentam que o auto emprego está associado a crises nos salários dos indivíduos, precarização do trabalho e queda na quantidade e qualidade dos empregos assalariados. Assim, considera-se que as principais razões para a teoria de push estão relacionadas

[...] a fatores estruturais, tais como a globalização e o grande número de projetos de downsizing realizados pelas empresas nos últimos tempos, o que teria compelido muitos indivíduos a migrarem para esta condição (um movimento do tipo push) (SILVA, 2008, p.218).

Portanto, na teoria de push, os indivíduos são empurrados para o auto emprego, ou seja, o auto emprego serve como alternativa quando não há saídas. Os indivíduos ao migrarem para o auto emprego nestas condições, não estão em busca de salários melhores ou jornadas de trabalhos que sejam mais atrativas, mas sim pela falta de estrutura encontrada no trabalho assalariado. Conforme Pamplona (2001 p.4-5), "mudanças estruturais da economia, a recessão, o desemprego 'empurrariam' as pessoas para o auto-emprego". Em outras palavras, segundo a teoria de push o auto emprego é decorrente da insegurança encontrada no mercado de trabalho.

Posto isso, Pamplona (2001) afirma que seguindo a teoria de push o indivíduo não necessita de habilidades para tornar-se um auto empregado, uma vez que indivíduos necessitam apenas de um "impulso" oriundo das condições no qual o indivíduo se encontra. Nesse sentido o indivíduo é empurrado pelas 
circunstâncias do mercado de trabalho, visto que por escolha própria, não deixaria o trabalho assalariado para tornar-se um auto empregado.

Em resumo, a teoria de pull indica que o auto emprego é visto de uma forma otimista onde, os indivíduos são atraídos voluntariamente para a exercício do auto emprego, seja pela oportunidade de maiores rendas ou jornadas de trabalho. Logo, essa teoria mostra-se favorável ao auto emprego em razão de considerar que o auto emprego é decorrente da dinâmica do mercado de trabalho. Contudo, para a teoria push, considera-se o auto emprego de forma pessimista, onde os indivíduos são puxados de forma involuntária para a prática do auto emprego, sendo essa uma saída para a falta do trabalho assalariado e a insegurança do mercado de trabalho.

\subsection{Determinantes do auto emprego}

Em geral, o auto emprego possui alguns determinantes básicos, ou seja, considera-se a existência de fatores em comum para que os indivíduos busquem essa modalidade, ou migrem para ela. Assim, classifica-se os fatores condicionantes do auto emprego em duas categorias. De um lado, trata-se dos aspectos individuais, ou microeconômicos, e do outro os aspectos coletivos ou macroeconômicos. Portanto, a partir destes fatores, avalia-se probabilidade da migração ou inserção do indivíduo no auto emprego.

Do ponto de vista microeconômico, de acordo com Araujo (2012), considera-se a educação, a idade, o estado civil, a posição familiar, o gênero e o número de dependentes como variáveis importantes na decisão individual pela inserção no mercado de trabalho. Logo, essas variáveis são consideradas condicionantes ao auto emprego, uma vez que o nível de educação, o gênero e a idede, por exemplo, influenciam as chances de inserção no mercado de trabalho, e as responsabilidades em relação à família tendem a diminuir no indivíduo a propensão ao risco, favorecendo a escolha por vínculos trabalhistas, sempre que possível. Por sua vez, Gomes (2009) adiciona fatores como raça ou etnia, predisposição transmitida por familiares, habilidades individuais e as atitudes e comportamentos do indivíduo, como fatores que influenciam a decisão de tornar-se auto empregado.

Do ponto de vista macroeconômico, os fatores mais relevantes estão relacionados às condições econômicas, ou seja, situações que afetam toda a sociedade simultaneamente. Nestes casos, o auto emprego não representa necessariamente como uma alternativa ao indivíduo, mas sim, em algumas situações, a única opção de geração de renda. Ainda de acordo com Gomes (2009), os principais fatores macroeconômicos que influenciam a decisão pelo auto emprego são o nível de desenvolvimento da economia, a situação macroeconômica corrente e esperada (recessão, desemprego, crescimento), a legislação sobre o mercado de trabalho e sobre as empresas de pequeno porte, os incentivos legais, financeiros e sociais ao empreendedorismo, entre outros. Cabe ressaltar que, neste estudo, o foco se dá sobre os determinantes microeconômicos. 


\section{Metodologia Empírica}

O objetivo deste estudo é avaliar os determinantes do auto emprego em Mato Grosso de duas maneiras. Em primeiro lugar, pretende-se analisar quais fatores microeconômicas influenciam em maior medida a opção pelo auto emprego, e em segundo lugar, considerando a evolução no mercado de trabalho local nos últimos anos, busca-se avaliar se houve alterações nestas condições. Portanto, o estudo baseia-se em dois cortes temporais, considerando os anos de 2004 e de 2012, e assim, avalia-se os efeitos dos mesmos fatores nestes dois períodos. A escolha destes dois anos se deu pela disponibilidade de dados, pois, apesar dos dados do PNAD serem disponibilizados anualmente, nestes anos foram encontradas as variáveis apropriadas para o modelo proposto. Ainda, foram considerandos estes dois anos em particular por representarem um período de relativa estabilidade no mercado de trabalho.

Em termos empíricos, o modelo avaliado é expresso da seguinte forma:

$$
y=\beta_{j} X_{j i}+\varepsilon_{i}
$$

onde y é a variável dependente binária que descreve se o indíviduo é ou não auto empregado, $\beta_{j}$ é um vetor de parâmetros associados às variáveis explicativas $X_{j i}$, e $\varepsilon_{i}$ é um termo de erro aleatório. Como variáveis explicativas, considera-se o gênero do indivíduo, a raça, se alfabetizado ou não, o nível de escolaridade, se trabalhador agrícola ou não, e o nível de renda familiar per capita.

Tendo em vista que a função de uma variável dummy no moledo é classificar o indivíduo de acordo com determinadas características qualitativas, considera-se este procedimento para algumas variáveis. Assim, para ambos os anos analisados, as seguintes variáveis binárias foram construídas, com base nos dados da PNAD (entre parenteses o código de cada variável): i) gênero - 1 se feminino (V0302); ii) raça - 1 se branca (V0404); iii) alfabetizado - 1 se sim (V0601); iv) emprego - 1 se não auto empregado (V4746); v) atividade - 1 se não agrícola (V4808).

Adicionalmente, com base na variável anos de estudo (V4703), foram construídas variáves para nível de educação, considerando nível básico se 0 número de 4 anos ou menos de estudo, e nível superior se mais de 15 anos de estudo. Em relação ao nível de estudo, estima-se dois modelos distintos, um com o nível baixo de formação e outro com nível superior, ambos considerando dados binários, sendo 1 se dada a característica e zero caso contrário. Para a variável nível de renda familiar, foi considerada a série de rendimento mensal domiciliar per capita (V4742).

Posto que trata-se de um modelo de probabilidade linear, faz-se as estimativas via logit, que contorna alguns problemas da regressão tradicional, como a ausência de normalidade, a heterocedasticidade e a possibilidade da probabilidade não situar-se entre zero e um. Este modelo é bastante difundido na literatura e bem documentado em referências tradicionais de econometria [Ver Gujarati (2006); Wooldridge (2006)] 
Conforme ressaltado, os dados foram extraídos da Pesquisa Nacional de Amostras de Domicílios (PNAD), para os anos de 2004 e 2012. Para os propósitos deste estudo, importa considerar a parcela da população economicamente ativa de Mato Grosso, que em 2004 era de 66\% e em 2012, de $68 \%$.

Tabela 1: Estatísticas Descritivas

\begin{tabular}{l|c|c}
\hline Relações entre Dados da PNAD & $\mathbf{2 0 0 4}$ & $\mathbf{2 0 1 2}$ \\
\hline PEA / População & $66 \%$ & $68 \%$ \\
\hline Auto Emprego / PEA & $50 \%$ & $62 \%$ \\
\hline Atividade Não Agrícola / PEA & $70 \%$ & $81 \%$ \\
\hline Auto Emprego / PEA Não Agrícola & $53 \%$ & $64 \%$ \\
\hline
\end{tabular}

Fonte: PNAD (2004, 2012). Dados compilados pelos autores (2015).

Ademais, para efeitos desta pesquisa, o auto emprego é definido como a ocupação na qual o indivíduo possui como principal característica de trabalho a autonomia, detendo o capital físico e o capital humano, podendo ocorrer nos meios rurais, nos negócios e no comércio. Em relação à renda, espera-se que o indivíduo auto empregado obtenha rendimentos para a subsistência, ou seja, sem excedentes. Contudo, pode ser considerado auto empregado também aquele indívíduo que busca nesta modalidade de ocupação ganhos maiores frente aos oferecidos no trabalho assalariado. Assim, a característica fundamental do auto emprego é a ausência de vincúlos trabalhistas de acordo com as normas da legislação.

No contexto da PNAD, são considerados auto empregados os indívudos com as seguintes ocupações: i) trabalhador doméstico sem carteria de trabalho assinada; ii) trabalhador por conta própria; iii) trabalhador na produção para 0 próprio consumo; iv) trabalhador na construção para uso próprio; $v$ ) outro empregado sem carteira de trabalho assinada; $\mathrm{e} v$ ) trabalhador não remunerado. Logo, empregados com carteira assinada, militares, funcionários públicos estatuários e trabalhadores domésticos com carteira de trabalho assinada são considerados, neste estudo, indíviduos não auto empregados.

\section{Análise e Interpretação dos Resultados}

Conforme descrito, os dados foram extraídos da Pesquisa Nacional de Amostras de Domicílios (PNAD), sendo considerados para a pesquisa os anos de 2004 e 2012, posto que o objetivo foi avaliar a mudança no mercado de trabalho ocorrida ao longo deste periodo no estado. Para os propósitos deste estudo, o importante é considerar a parcela da População Economicamente Ativa, ou seja, aqueles indivíduos que estejam trabalhando ou à procura de trabalho/emprego, sendo esses os classificados 'auto emprego' e 'não auto emprego'. Nesse sentido, o Quadro 1 discrimina os grupos de atividades descritas no PNAD nestas duas classificações.

Seguindo esta discriminação, com base nos dados da PNAD, observa-se que em 2004 o percentual de indivíduos no mercado de trabalho de Mato Grosso 
classificados como auto empregado era de 50\%, em em 2012, este percentual se elevou para $62 \%$.

Quadro 1: Componentes do grupo Auto Emprego e Não Auto Emprego.

\begin{tabular}{|l|l|}
\hline \multicolumn{1}{|c|}{ Auto emprego } & \multicolumn{1}{|c|}{ Não auto emprego } \\
\hline $\begin{array}{l}\text { Outro empregado sem carteira de trabalho assinada } \\
\text { Trabalhador doméstico sem carteira de trabalho } \\
\text { assinada }\end{array}$ & $\begin{array}{l}\text { Empregado com carteira de trabalho assinada } \\
\text { Militar }\end{array}$ \\
$\begin{array}{l}\text { Conta própria } \\
\text { Trabalhador na produção para o próprio consumo }\end{array}$ & $\begin{array}{l}\text { Funcionário público estatutário } \\
\text { Trabalhador doméstico com carteira de trabalho } \\
\text { assinada }\end{array}$ \\
$\begin{array}{l}\text { Trabalhador na construção para o próprio uso } \\
\text { Não remunerado }\end{array}$ & \\
\hline
\end{tabular}

Nestas condições, este estudo propõem que o indivíduo possua determinadas carcterísticas como determinantes da probabilidade de optar pelo auto emprego, sendo estas as variáveis explicativas do modelo empírico. Assim, considera-se as variáveis gênero, raça, alfabetização, nível de educação, trabalho não agrícola e renda domiciliar per capita.

Inicialmente, o modelo empírico é estimado considerando o nível de educação básica como um dos fatores determinantes da probabilidade de 0 indivíduo estar auto empregado. Os resultados são reportados na Tabela 2 , com estimatvias para os anos de 2004 e de 2012.

Tabela 2: Modelo Estimado Considerando Nível Básico de Educação

\begin{tabular}{cccccccc}
\hline & $\boldsymbol{P r}(\boldsymbol{y})$ & Gênero & Branca & Alfabetizado & Básico & Agrícola & Rendimento \\
\hline \multirow{2}{*}{2004} & \multirow{2}{*}{0.62} & 0.006 & 0.030 & $-0.089^{* *}$ & 0.035 & $0.084^{* * *}$ & -0.000008 \\
& & $(.02148)$ & $(.02167)$ & $(.04077)$ & $(.02536)$ & $(.02506)$ & $(.00002)$ \\
\hline \multirow{2}{*}{2012} & \multirow{2}{*}{0.47} & $0.111^{* * *}$ & $-0.035^{\star *}$ & $-0.142^{* * *}$ & $0.189^{* * *}$ & $0.161^{* * *}$ & $-0.00002^{* * *}$ \\
& & $(.01802)$ & $(.01804)$ & $(.04698)$ & $(.02404)$ & $(.02288)$ & $(.00001)$
\end{tabular}

Fonte: PNAD (2004, 2012). Modelos Logit Estimados por Máxima Verossimilhança. O desvio pardrão estão reportados entre parenteses. ${ }^{* * *},{ }^{* *} \mathrm{e}$ * representam significância estatística a $1 \%, 5 \%$ e 10\%, respectivamente.

O modelo considerou o fato de o indivíduo ser do gênero feminino, da raça branca, ser alfabetizado, possuir nível básico de educação e ser trabalhador não agrícola, como variáveis qualitativas que indicam a probabilidade deste tornarse auto empregado, além da renda domiciliar per capita. Com estas características, em 2004, a probabilidade do indivíduo estar no auto emprego foi de $62 \%$, enquanto que em 2012 , essa probabilidade cai para $47 \%$.

Com realação ao modelo estimado para 2004, individualmente, o fato de o indíviduo ser mulher, caucaseano, possuir nível básico de educação e as condições de renda familiar, não se mostraram determinantes estatissticamente signifantes para a opção pelo auto emprego. Entretanto, o fato de o indivíduo ser alfabetizado diminui a probabilidade do auto emprego, e por ser trabalhado não agrícola, o auto emprego é relativamente mais provável. 
Considerando o modelo estimado para 2012, entretanto, todas as variáveis foram significativas. As características ser mulher, possuir o nível básico de educação e ser trabalhador não agrícola, elevam a probabilidade de o indivíduo optar pelo auto emprego. Em contrapartida, ser da raça branca e ser alfabetizado tem o efeito de reduzir a probabilidade do auto emprego. A variável renda familiar também foi estatísticamente significativa, indicando que quanto maior a renda per capita da família, menor a probabilidade do indivíduo estar auto empregado.

$\mathrm{Na}$ sequência, considera-se o nível de educação superior como determinante da probabilidade de o indivíduo estar auto empregado, em substituição ao nível básico. Os resutaldos são apresentados na Tabela 3, também com estimações para 2004 e 2012. O modelo considerou o fato de 0 indivíduo ser do gênero feminino, da raça branca, ser alfabetizado, possuir nível superior de educação e ser trabalhador não agrícola, como variáveis qualitativas que indicam a probabilidade deste tornar-se auto empregado, além da renda domiciliar per capita.

Observa-se que neste caso, considerando estas características, a probabilidade do indivíduo estar auto empregado é a mesma tanto para 2004 (62\%), quanto para 2012 (47\%).

Em relação ao modelo estimado para 2004, individualmente, o fato de o indíviduo ser mulher, caucaseano, possuir nível superior de educação e as condições de renda familiar, não são determinantes para a opção pelo auto emprego. Entretanto, o fato de ser não alfabetizado e/ou ser trabalhador não agrícola, aumenta a probabilidade do auto emprego. Nota-se que este resultado é relativamente o mesmo do encontrado com a estimação anterior.

Considerando o modelo estimado para 2012, contudo, um número maior de variáveis mostrou-se signficativas, quais sejam, gênero, alfabetização, nível de educação e trabalho não agrícola. O fato do indivíduo ser mulher e trabalhador não agrícola elevam a probabilidade da opção pelo auto emprego, enquanto que ser alfabetizado e possuir nível superior de educação reduzem essa probabilidade. As variáveis raça e renda familiar não forma significativas neste caso.

Tabela 3: Modelo Estimado Considerando Nível Superior de Educação

\begin{tabular}{cccccccc}
\hline & $\boldsymbol{P r}(\boldsymbol{y})$ & Gênero & Branca & Alfabetizado & Superior & Agrícola & Rendimento \\
\hline \multirow{2}{*}{2004} & \multirow{2}{*}{0.62} & 0.00 & -0.030 & $-0.107^{* * *}$ & -0.012 & $0.074^{* * *}$ & -0.000008 \\
& & $(.02158)$ & $(.02167)$ & $(.03733)$ & $(.04035)$ & $(.02394)$ & $(.00002)$ \\
\hline \multirow{2}{*}{2012} & \multirow{2}{*}{0.47} & $0.127^{* * *}$ & -0.023 & $-0.259^{* * *}$ & $-0.212^{* * *}$ & $0.184^{* * *}$ & -0.00008 \\
& & $(.01829)$ & $(.01818)$ & $(.03716)$ & $(.02362)$ & $(.02198)$ & $(.00001)$ \\
\hline
\end{tabular}

Fonte: PNAD (2004, 2012). Modelos Logit Estimados por Máxima Verossimilhança. O desvio padrão estão reportados entre parenteses. ${ }^{* *},{ }^{* *} \mathrm{e}^{*}$ representam significância estatística a 1\%,5\% e 10\%, respectivamente.

Com base nestas estimativas, é possível observar algumas características importantes no mercado de trabalho matogrossense. Em 2004, por exemplo, o gênero do trabalhador não influenciava na opção pelo auto emprego. Contudo, em 2012, o fato do indivíduo ser do gênero feminino elevava as chances deste ingressar no auto emprego, isso considerando constantes as demais variáveis, dado que a probabilidade marginal em 2012 foi muito significativa. Tal fato, pode ser justificado através da teoria, visto que o auto emprego pode ser considerado 
uma saída para as mulheres que possuem família, principalmente se tiverem filhos e se precisam contribuir para renda familiar. Assim, o auto emprego passa a ser uma opção de renda que, dado a flexibilidade de horário, permite conciliar os cuidados e a educação infantil.

No tocante à alfabetização, observa-se que o fato de o indivíduo saber ler e escrever reduz as chances deste tornar-se auto empregado. Isso demonstra que o ingresso no mercado de trabalho é facilitado caso o indivíduo seja alfabetizado, mesmo que minimamente. Uma possível justificativa para isso é que o mercado formal de trabalho em Mato Grosso ainda está em expansão, e há espaço para trabalhadores com poucas instruções, sendo privilegiados àqueles com o nível mínimo de alfabetização. Logo, aqueles não alfabetizados acabam optando pelo auto emprego como alternativa ao trabalho assalariado.

Posto isto, cabe analisar o nível de educação. Comparativamente, os trabalhadores com nível básico de ensino são mais propensos ao auto emprego do que aqueles trabalhadores com nível superior. Isso corrobora o fato de que no mercado de trabalho formal em Mato Grosso, indivíduos com maior nível de escolaridade possuem mais chances de se inserir.

Em resumo, ao analisar o nível de estudo, observa-se os indivíduos que possuem nível básico estão mais propensos ao auto emprego do que aqueles com nível superior. Dessa forma, as variáveis alfabetização e nível de educação em anos de estudo são justificadas pela teoria, visto que, os indivíduos com altos níveis educacionais estão menos propensos a migrar para o auto emprego, sendo que em média os rendimentos familiares por eles obtidos encontram-se superiores ao demais indivíduos que possuem níveis educacionais menores.

Em relação à atividade exercída pelo indivíduo, o fato dela não ser agrícola eleva as chances da opção pelo auto emprego em todas as estimativas realizadas. Isso pode decorrer de vários fatores, dentre eles, cabe destaque à dois. O primeiro, conforme já destacado, a agricultura no estado é relativamente extensiva, o que faz com que seja estruturado um mercado formal de trabalho no campo, diminuindo a probabilidade de auto emprego em atividades agrícolas. Segundo, dado que a maior parte da população economicamente ativa é não agrícola, há maiores chances dessa parcela participar de atividades consideradas auto emprego.

Outro aspecto muito importante, é a questão da renda familiar. De acordo com as estimativas, apenas quando o indivíduo possui nível básico de educação, essa variável é determinante para a opção pelo auto emprego. No contrário, possuindo o indivíduo nível superior, a renda familiar não tem efeitos sobre a probabilidade do auto emprego. Quanto a isso, pode-se argumentar que famílias cujos indivíduos possuem educação superior, têm um nível de renda relativamente maior. Logo, é provável que a opção pelo auto emprego decorra de outros fatores que não seja a necessidade de complementação da renda familiar.

Neste contexto, pode-se inferir que a opção pelo auto emprego no estado de Mato Grosso pode ser considerada mais uma alternativa à dificuldade de inserção no mercado de trabalho formal do que a busca por renda superior à dos trabalhos assalariados. 
Assim, de modo geral, ao analisar este problema sob a ótica das duas teorias descritas anterioremente, observa-se que a teoria de push é melhor empregada para a explicar a ocorrência do auto emprego no mercado de trablaho em Mato Grosso. Em resumo, o auto emprego é decorrente da dinâmica do mercado de trabalho no estado, e é considerado sob uma ótica pessimista, onde os indivíduos são empurrados para o auto emprego em função das limitações encontradas para a inserção no mercado de trabalho formal.

\section{Considerações finais}

Este estudo procurou avaliar os determinantes microeconômicos do auto emprego no mercado de trabalho formal de Mato Grosso. Tendo em vista que este tipo de ocupação tem aumentado percentualmente entre a população economicamente ativa, o intuíto foi avaliar quais os fatores são responsáveis, ou ao menos influentes, na escolha pelo auto emprego.

Das características consideradas no modelo empírico, observou-se que o nível de educação é um fator importante ao explicar o auto emprego, sendo que quanto maior o grau de escolaridade do indivíduo, menor será a probabilidade deste optar pelo auto emprego. Outro ponto importante na análise, foi que a renda domiciliar per capita praticamente não teve efeitos sobre a opção pelo auto emprego. Em contrapartida, a variável gênero se tornou mais importante neste caso nos últimos anos. Para o ano de 2012, o fato de o indivíduo ser mulher elevavam as chances deste optar pelo auto emprego, enquanto que em 2004, isso não era relevante.

Quanto a variável raça, esta não demonstrou-se significativa em nenhum dos modelos estimados, para ambos os anos. Dessa forma, a teoria que determina a discriminação racial como determinante da opção pelo auto emprego por indivíduos não brancos não é observada no mercado de trabalho mato grossense nesse período.

Por fim, dados os resultados, fica evidente que para o mercado de trabalho de Mato Grosso, o auto emprego é melhor explicado pelos argumentos da teoria push, onde opção por este tipo de ocupação é mais uma resposta às dificuldades de inserção do mercado formal do que à busca por melhores oportunidades. Cabe ressaltar que estes resultados vêm de uma análise pontual em dois instantes de tempo. Uma análise mais ampla e contínua pode ser realizadas em estudos futuros para explicar como essas mudanças observadas ocorreram no período, incluíndo dados mais recentes que estejam disponíveis, e metodologias mais robustas para a análise desta questão.

\section{REFERÊNCIAS}

ANDERSON, P.; WADENSJO, E. Employees who become self-employed: do labour income and wages have na Impact? Bonn - Alemanha - Iza Discussion paper no. 1971, 2006;

ARAUJO, H., Ramos, C. Alberto. Análise dos factores determinantes do auto-emprego em Portugal. Texto para discução no 657, Instituto de Pesquisa Economica Aplicada IPEA, Rio de Janeiro, 1999; 
ARAUJO, $\mathrm{H}$. Mestre, Análise dos factores determinantes do auto-emprego em Portugal, 2012. 79f. Tese de Mestrado em Economia da Empresa e da Concorrência. Departamento de economia Instituto Universitário de Lisboa, Lisboa 2012;

BALKIN, Steven. Self-employment for low-Income peolpe. Nova lorque: Praeguer, 1989;

BLANCHFLOWER, David. Entrepreneurship in the United States. Bonn (Alemanha): IZA Discussion Paper No 3130, 2007;

GOMES, Rodrigo Campos. O auto-emprego no Brasil: uma análise dos fatores determinantes. 2009. 120f. Dissertação. Mestrado em Economia Política. Programa de pós graduação em Economia Política, Pontifícia Universidade Católica - (PUC), São Paulo, 2009;

GUJARATI, Damolar. Econometria Básica. Tradução Maria José Cyhlar. 4ª ed; Rio de Janeiro: Elsivier, $20065^{\text {a }}$ triagem;

HENREKSON, Magnus. Comment on David G. Blanchflower: Is more self-emproyment good ou bad? Swedish Economic Policy Review. Estocolmo, vol. 11, no 2, 2004;

HIRSCHMAN, A. O. Estratégia do desenvolvimento econômico. Rio de Janeiro: Fundo de Cultura, 1961. Edição original de 1958;

HIPPIE, S. Self-employment in the United States: na update. Monthly Labor Review, v. 127, n.7, pp. 13-23, jul. 2004;

IBGE. PNAD - Pesquisa Nacional por Amosta de Domicílios: Dicionário de Variáveis 2004. Disponível em: $<$ http://downloads.ibge.gov.br/downloads_estatisticas.htm?caminho=Trabalho_e_Rendimento/P esquisa_Nacional_por_Amostra_de_Domicilios_continua/Microdados/>. Acesso em $30 \mathrm{mar}$. 2015;

IBGE. PNAD - Pesquisa Nacional por Amosta de Domicílios: Dicionário de Variáveis 2012. Disponível em: $<$ http://downloads.ibge.gov.br/downloads_estatisticas.htm?caminho=Trabalho_e_Rendimento/P esquisa_Nacional_por_Amostra_de_Domicilios_continua/Microdados/>. Acesso em $30 \mathrm{mar}$. 2015;

MATKOVIC, Teo. Different ways of being one's own boss: patterns of self-employment in croatia. Oxford: University of Oxford, 2004;

NERI, Marcelo. Equação de salários Minceriana. Fundação Getulio Vargas - FGV -, sd. Disponível em <cps/pesquisas/Politicas_sociais_alunos/2011/pdf/BES_EquacaoMinceriana.pdf $>$ Acesso em: 07 fev.2015;

OIT. Key indicators of the labour Market. 5 ed. Genebra: OIT, 2007a;

PAMPLONA, João Batista. Erguendo-se pelos próprios cabelos: auto-emprego e reestruturação produtiva no Brasil.São Paulo: Germinal 2001;

PARKER, Simon C. The Economics of Self-Employment and Entrepreneurship. Cambridge: Cambridge University Press, 2004;

PEASE, C. M., BULL, J. M. A template for scientific inquiry.Disponível em<http://www.utexas.edu>Acesso em 03 fev. 2015;

PERULLI, Adalberto. Economically dependent / quase-subordinate ( parasubordinate) empoyment: legal, social and economic aspects. Paris: European Commission, Committee for Employmenr and Social Affairs, 2003; 
SILVA, José Roberto Gomes da. Profissionais qualificados e experiencia de auto-emprego: questões de temp e espaço. Rio de Janeiro, REAd -59 ed, vol. 14, no 1, 2008. 